\title{
A Relação entre Ativos Intangíveis, Dívida e Criação de Valor para as Companhias de Capital Aberto atuantes no Brasil
}

\section{The Relationship between Intangible Assets, Debt and Value Creation for the Publicly Held Companies acting in Brazil}

\author{
Douglas Dias Bastos ${ }^{1 *}$, Isabela Lopes Abreu ${ }^{1}$ \\ ${ }^{1}$ Universidade Presbiteriana Mackenzie.
}

\begin{tabular}{l} 
I N F O A R T I G O \\
\hline Palavras-chave: \\
Intangíveis; \\
Dívida; \\
Valor; \\
Dados em painel.
\end{tabular}

\begin{abstract}
RESUMO
O presente trabalho tem por objetivo investigar a relação entre ativos intangíveis, dívida e criação de valor para as empresas de capital aberto. Estudos empíricos anteriores evidenciam que empresas com maior grau de intangibilidade são menos endividadas e tendem a criar valor. Com uma amostra composta por 261 empresas não financeiras de capital aberto, analisada no período de 2009 a 2016, utilizou-se regressão com dados em painel pooled e com efeitos fixos para mensurar as relações entre ativos intangíveis e criação de valor, dívida e criação de valor e ativos intangíveis e dívida. Os resultados indicam que há uma relação direta e estatisticamente significante entre ativos intangíveis e criação de valor. Verificou-se uma relação negativa e estatisticamente significante entre dívida e criação de valor. Por fim, verificou-se uma relação dúbia entre ativos intangíveis e dívida contábil e dívida a valor de mercado.
\end{abstract}

\begin{tabular}{l}
\hline A R T I C L E I N F O \\
\hline Keywords: \\
Intangible; \\
Debt; \\
Value; \\
Panel data.
\end{tabular}

\begin{abstract}
A B S T R A C T
This paper aims to investigate the relationship between intangible assets, debt and value creation for publicly traded companies. Previous empirical studies show that companies with a higher degree of intangibility are less debt and tend to create value. With a sample of 261 publicly traded non-financial companies, analysed from 2009 to 2016, regression was used with pooled panel data and fixed effects to measure the relationship between intangible assets and the creation of value, debt and creation of value and intangible assets and debt. The results indicate that there is a direct and statistically significant relationship between intangible assets and value creation. There was a negative and statistically significant relationship between debt and value creation. Finally, there was a dubious relationship between intangible assets and book debt and market debt.
\end{abstract}

\footnotetext{
* Correspondência para autor: douglas.bastos@mackenzie.br (Bastos, D. D.), isabela_lopes_abreu@hotmail.com (Abreu, I. L.).
} 


\section{Introdução}

O estudo contínuo das ciências de toda e qualquer área é fator predominante para proporcionar o seu desenvolvimento. Assim, considerando a importância das finanças para as empresas e outras organizações, este estudo busca analisar sistematicamente alguns fatores que podem influenciar o valor das empresas, como a intangibilidade e o endividamento. Estes dois fatores são constantemente pesquisados no campo de finanças corporativas.

O valor econômico de uma empresa é resultado da soma dos seus ativos tangíveis e intangíveis. De acordo com Kayo et al (2006), a influência relativa dos ativos intangíveis sobre a criação de valor das empresas pode variar por diversos motivos: em função do setor de atividade, do ciclo de vida do produto e da empresa, da missão das empresas, entre outros. Portanto, em função da grande valorização dos ativos intangíveis das empresas, torna-se importante entender como gerenciá-los de forma a criar valor para as empresas.

Uma questão desafiadora envolve identificar as variáveis que podem ser consideradas intangíveis para as empresas e como mensurar economicamente os ativos intangíveis. Muitos estudos anteriores sobre o tema utilizam algumas variáveis proxy para chegar o mais próximo possível do capital intangível, para assim, conseguir encontrar algumas evidências acerca de seu valor econômico.

Lev (2001) faz uma associação entre ativos intangíveis e valoração econômica da empresa. Dessa maneira, ativos intangíveis, tais como P\&D (Pesquisa e Desenvolvimento), propaganda (apoio à marca), despesas de capital, sistemas de informação e aquisição de tecnologia contribuiriam para a valoração econômica da empresa. Portanto, boa parte do valor de mercado de uma empresa advém dos seus ativos intangíveis. Em um ambiente econômico cada vez mais competitivo, o domínio do capital intelectual, por parte das empresas, impulsiona seu valor de mercado. Desse modo, sugere-se uma relação positiva entre decisões de investimentos em intangíveis e valor de mercado da empresa.

A forma de financiamento da empresa é um assunto amplamente investigado em pesquisas empíricas na área de finanças corporativas. Existem algumas correntes teóricas que procuram explicar a estrutura de capital das empresas (MODIGLIANI; MILLER, 1958; MYERS; MAJLUF, 1984; RAJAN; ZINGALES, 1995; FRANK; GOYAL, 2003; LEMMON; ZENDER, 2010).

As duas principais correntes teóricas sobre estrutura de capital são a teoria do trade off, que defende a existência de uma estrutura ótima de capital, gerada pelo trade off entre o benefício fiscal da dívida e os custos de dificuldades financeiras.

Para teoria do trade off, o valor da empresa é composto por três partes: $(i)$ valor da empresa desalavancada (financiada completamente por capital próprio) mais (ii) o valor do benefício físcal da dívida; e menos (iii) os custos de dificuldades financeiras (custos direto e indiretos de falência e custos de agência).

A teoria do pecking order determina uma hierarquia das fontes de financiamento das empresas. Myers (1984) desenvolveu formalmente essa corrente teórica ao mostrar que a estrutura de capital de uma empresa resulta de decisões que seguem uma ordem de preferência na escolha dos recursos financeiros. De modo geral, as empresas optariam em primeiro lugar por recursos financeiros internos, seguido de dívidas e por fim, a emissão de ações. Para Myers e Majluf (1984), tal ordem (hierarquia) resulta da assimetria de informação entre gestores e agentes externos, e sinalização ao mercado que a empresa faz quando da busca por recursos financeiros.

No tocante ao endividamento da empresa, alguns estudos, como o de Kayo, Teh e Basso (2006) revelam que a intangibilidade possui uma relação negativa com o endividamento, e que alguns ativos intangíveis mostram-se importantes na determinação da estrutura de capital. Jucá et. al. (2016) citam que os ativos tangíveis (estoques e imobilizado) são bons colaterais exatamente por servirem como garantias às dívidas contraídas, e por isso seriam um fator relevante para o aumento do endividamento da empresa. No entanto, os ativos intangíveis, em tese, não servem como bons colaterais dados como garantia de contração de dívida, levando empresas com elevados intangíveis a se endividarem menos. Como os ativos intangíveis são altamente específicos, os credores não aceitariam esses ativos como garantia às dívidas.

O objetivo geral do presente estudo é investigar a relação entre ativos intangíveis, dívida e criação de valor para as empresas de capital aberto. Ademais, este trabalho pretende responder à seguinte pergunta- 
problema: Qual a relação entre ativos intangíveis, dívida e criação de valor de mercado para as empresas de capital aberto no Brasil?

O objetivo específico tem como finalidade i) entender a relação entre ativos intangíveis e criação de valor de mercado da empresa, ii) entender a relação entre dívida e criação de valor de mercado da empresa e iii) entender a relação entre ativos intangíveis e dívida das empresas.

Para tanto, justifica-se a importância das conclusões geradas pelo presente trabalho, uma vez que, com elas, haverá possibilidade de corroborar ou refutar estudos anteriores que pesquisaram a relação entre dívida, intangibilidade e criação de valor. Esta pesquisa investiga de forma mais atual estas relações simultaneamente, a partir de outras variáveis de estudo, e com a utilização de dados em painel.

\section{Referencial Teórico}

Há necessidade de um maior entendimento sobre ativos intangíveis. No aspecto contábil, o Comitê de Pronunciamentos Contábeis (CPC), trata no CPC 04 sobre ativo intangível. Um ativo intangível é um ativo não monetário identificável sem substância física. Um ativo intangível deve ser reconhecido apenas se: i) for provável que os benefícios econômicos futuros esperados atribuíveis ao ativo serão gerados em favor da entidade; e ii) o custo do ativo possa ser mensurado com confiabilidade. Entretanto, mensurar o valor de mercado dos ativos intangíveis é um desafio, uma vez que o valor da conta Intangível inserida no grupo Ativos Não-Circulantes do Balanço Patrimonial não capta o seu atual valor de mercado. Sendo assim, há necessidade de criar uma variável proxy para captar o valor dos intangíveis.

\subsection{Ativos Intangíveis e Valor}

O ativo intangível traz valor para as empresas, o qual muitas vezes é dificultoso sua mensuração econômica. Isto pode ser explicado pelo trabalho de Lev (2001), o qual mostra que o índice valor de mercado/valor contábil das empresas subiu de 1 para 6 de 1980 a 2001. Alguns autores tentam determinar quais são os ativos considerados intangíveis nas empresas, e também, tentam mensurar economicamente esses ativos. Segundo Lev (2001) os ativos intangíveis são benefícios futuros que não possuem corpo físico ou financeiro, associado à $\mathrm{P} \& D$, propaganda, despesas de capital, sistemas de informação e aquisição de tecnologia à intangibilidade.

De acordo com Kayo, Patrocínio e Martin (2006), os ativos intangíveis são definidos e divididos em quatro tipo de ativos: Ativos humanos (conhecimento, talento, capacidade, habilidade, experiência dos funcionário, administração superior, treinamento e desenvolvimento); Ativos de inovação (pesquisa e desenvolvimento, patentes, fórmulas secretas e know-how tecnológico); Ativos estruturais (processos, softwares proprietários, banco de dados, sistemas de informação e administrativos, inteligência de mercado e canais de mercado); e Ativos de relacionamento (marcas, logos, trademarks, direitos autorais e contratos).

Outra questão reside na relação entre intangibilidade e valor de mercado da empresa. Alguns autores buscaram investigar esta hipótese também, tais como Saliba et al. (2013), Perez e Famá (2006), Perez e Famá (2015), Medrado et at. (2016) e Sprenger et al. (2017), entre outros.

O trabalho de Saliba et al. (2013) teve a finalidade de mensurar os ativos intangíveis de empresas norteamericanas. Segundo os autores, os ativos intangíveis foram vinculados à pesquisa e desenvolvimento, gastos com capital e gastos administrativos, gerais e com vendas. Os resultados obtidos confirmam que o retorno do acionista possui relação direta com o grau de intangibilidade.

Perez e Famá (2006) chegaram à conclusão de que o desempenho econômico-financeiro das empresas com alto grau de intangibilidade é melhor em comparação às empresas com grau de intangibilidade abaixo da mediana. Em outro estudo, Perez e Famá (2015), concluíram que existe uma relação direta entre ativos intangíveis e a criação de valor das empresas estudadas.

De acordo com Medrado et at. (2016), o desempenho econômico-financeiro das empresas é influenciado pelo nível de intangibilidade dos ativos e os autores confirmaram a hipótese de que os ativos intangíveis têm relação positiva com o market-to-book value, indicando que a intangibilidade presente nos ativos das 
empresas promovem a criação de valor das mesmas. Além disso, os autores também relacionaram a variável market-to-book value com variáveis de controle, encontrando os seguintes resultados:

Sprenger et al. (2017), a partir da teoria da Visão Baseada em Recursos, realizaram um estudo com o objetivo de corroborar a influência do grau de intangibilidade no desempenho econômico-financeiro em empresas dos países da América Latina. Mais uma vez, observou-se que o desempenho econômico é positivamente afetado pelo grau de intangibilidade. Além disso, os autores afirmaram que quanto mais intangíveis são as empresas, maior é a associação para gerar desempenhos superiores para estas. Portanto, Sprenger et al. (2017) puderam concluir que os ativos intangíveis são recursos diferenciais para as organizações e podem agregar valor.

\subsection{Estrutura de Capital}

Endividamento e estrutura de capital são assuntos amplamente pesquisados em finanças corporativas. O clássico artigo de Modigliani e Miller (1958), conclui que o valor de mercado não é determinado pela estrutura de capital, mas sim pelas decisões de investimento. No entanto, Modigliani e Miller (1963) avançam ao incluir no estudo o benefício fiscal da dívida, que pode gerar efeito positivo do endividamento sobre o valor de mercado da empresa.

Bessler et al. (2011) resumem as três correntes teóricas sobre estrutura de capital, reforçando que ainda não se tem uma única teoria completa que seja capaz de explicar efetivamente as decisões de financiamento das empresas. São elas:

1) Teoria do trade off: especifica que há um ponto ótimo de estrutura de capital, alcançado por meio do equilíbrio entre os custos de dificuldades financeiras (tendência à falência) e o benefício proporcionado por impostos que reduzem o custo da dívida.

2) Teoria do pecking order: postula que uma empresa típica levanta recursos financeiros seguindo uma ordem de preferência, com base na premissa principal da assimetria de informação entre gestores e mercado. Assim, não existiria um ponto ótimo de estrutura de capital.

3) Market timing: Mais recentemente, outro modelo foi proposto com base no comportamento do mercado de capitais em certos momentos. A estrutura de capital seria uma consequência de a empresa buscar o melhor momento de mercado para financiar seus investimentos, sem ter um objetivo definido quanto à composição de capital.

Myers (1984) constata que as empresas seguem uma ordem (hierarquia) para levantar fundos financeiros, optando primeiramente por fundos internos, depois dívida, e por último emissão de ações. Para empresas brasileiras, os trabalhos de Bastos e Nakamura (2009) e Correa, Basso e Nakamura (2013), evidenciam a teoria do pecking order.

Frank e Goyal (2009) investigaram quais são os determinantes (fatores) que realmente impactam a estrutura de capital. Em uma pesquisa que cobre o período de 1950 a 2003, o nível de endividamento a valor de mercado é afetado de forma mais intensa pelos seguintes fatores:

1) Tangibilidade: Empresas que detém mais ativos tangíveis tendem a ser mais endividadas, estando em linha com a teoria de pecking order;

2) Lucratividade: Empresas mais lucrativas tendem a possuir menos dívidas, também de acordo com o que prevê a pecking order;

3) Tamanho da firma: Empresas maiores (em termos de ativos) tendem a ser mais endividadas, indo à favor do trade off e refutando a pecking order;

4) Market-to-Book ratio: Empresas com maior market-to-book ratio tendem a ser menos endividadas. Aqui, tanto uma relação direta quanto indireta com o endividamento encontra respaldo pela pecking order. 
Resultados muito parecidos são encontrados por Brito, Corrar e Batistella (2007), Bastos e Nakamura (2009) e Correa, Basso e Nakamura (2013), para empresas brasileiras. Há uma relação inversa entre dívida e os fatores tangibilidade e lucratividade. O tamanho da empresa está diretamente relacionado com o endividamento e por fim, o market-to-book, apresenta uma relação dúbia com o nível de endividamento. Tais evidências reforçariam a predominância da teoria de pecking order no Brasil.

\subsection{Intangibilidade e Endividamento}

Esta seção traz à luz a relação entre estrutura de capital e intangibilidade. As evidências empíricas mostram que há uma relação negativa entre endividamento e intangibilidade. Myers (1984) sugere que empresas com maior porcentagem de ativos intangíveis são menos endividadas. Empiricamente, os trabalhos de Titman e Wessels (1988) e Faulkender e Petersen (2006) confirmam tal relação. Ainda de acordo com Balakrishnan e Fox (1993), Vicente-Lorente (2001) e O’Brien (2003) empresas com elevados investimentos em P\&D apresentam uma estrutura de capital com baixo nível de endividamento, em razão desse tipo de ativo intangível possuir baixa garantia para fins de tomada de dívida.

Para empresas atuantes no Brasil, Kayo e Famá (2004), Kayo, Teh e Basso (2006) e Kayo, Patrocínio e Martin (2009) também encontraram essa relação inversa.

De acordo com Kayo, Teh e Basso (2006), essa relação negativa entre o endividamento e os ativos intangíveis: patentes (representam os ativos de inovação) e marcas (representam o relacionamento com públicos alvo), pode ser explicada através da teoria do pecking order. Além disso, os autores puderam comprovar a hipótese de que as empresas inovadoras apresentam níveis mais baixos de endividamento. Adicionalmente, constataram que empresas de bem de consumo possuem uma média de quantidade de patentes mais alta, indicando serem mais inovadoras do que as de outros setores.

Essa conclusão indica que empresas inovadoras possuem uma dominância de capital próprio para financiar os investimentos. Bah e Dumontier (2001) justificam esse fenômeno por meio da teoria de agência, afirmando que esse fato pode ocorrer por conta do problema de substituição de ativos, da complexidade em garantir financiamentos com ativos intangíveis e pela dificuldade imposta pelo capital de terceiros em aceitar alguns projetos.

Kayo, Patrocínio e Martin (2009) desenvolveram um estudo com o objetivo de investigar a influência da estrutura de capital e dos ativos intangíveis sobre a criação de valor com foco em empresas adquirentes nos episódios de fusão e aquisição. Os autores concluem, entre outras evidências, que além da existência da relação negativa entre intangibilidade e endividamento, empresas intensivas em intangíveis priorizam uma maior folga financeira, resultando em criação de valor para a adquirente.

\section{Metodologia}

Este estudo possui a seguinte pergunta-problema: qual a relação entre ativos intangíveis, dívida e criação de valor de mercado para as empresas de capital aberto no Brasil?

As hipóteses de pesquisa foram desenvolvidas a partir da fundamentação teórica apresentada anteriormente, e são baseadas nas três principais variáveis deste estudo: endividamento, intangibilidade e valor de mercado. De acordo com os estudos de Patrocínio, Kayo e Kimura (2007), Saliba et al. (2013), Perez e Famá (2006), Perez e Famá (2015), Medrado et at. (2016) e Sprenger et al. (2017) foi elaborada a primeira hipótese:

- H1: há uma relação direta entre ativos intangíveis e criação de valor para as empresas, medido pelo market-to-book value.

A segunda hipótese foi desenvolvida por meio dos estudos de Perobelli e Famá (2002), Brito, Corrar e Batistella (2007), Bastos e Nakamura (2009) e Correa, Basso e Nakamura (2013), sendo:

- H2: há uma relação inversa entre dívida e criação de valor para as empresas, medido pelo market-to-book value. 
Considerando os estudos de Myers (1984), Lev (2001), Kayo e Famá (2004), Kayo, Teh e Basso (2006), Bah e Dumontier (2001), Kayo, Patrocínio e Martin (2009) e Kayo (2002), foi criada a terceira hipótese:

- H3: há uma relação inversa entre ativos intangíveis e dívida para as empresas.

\subsection{Composição da amostra, fonte e coleta de dados}

A amostra deste estudo compreende empresas brasileiras de capital aberto de diversos setores, excluindo os setores financeiros e afins. Tal exclusão se faz necessária, uma vez que a contabilidade bancária e suas demonstrações financeiras seguem padrões contábeis específicos, que diferem dos setores industriais e de comércio em geral. Inicialmente a amostra foi composta por 332 empresas de capital aberto. Os dados econômico-financeiros foram coletados do sistema Economática. Foram excluídas dessa primeira amostra empresas com dados faltantes (foram eliminadas da amostra empresas que possuíam menos de duas observações consecutivas) e aquelas cujo ativo total estava abaixo de \$ 50 milhões de reais/ano. Esse filtro é importante, pois de acordo com Brito, Corrar e Batistella (2007), a teoria dos custos de falência, empresas grandes, normalmente, são mais diversificadas do que empresas pequenas, estando menos sujeitas a dificuldades financeiras e possuindo custos de falência menores. Em razão disso, sua capacidade de endividamento é maior do que a das empresas pequenas. Adicionalmente, uma característica do mercado brasileiro é que as grandes empresas têm maior acesso a crédito de longo prazo do que as pequenas empresas, sobretudo por meio de Bancos de Desenvolvimento. As variáveis foram winsorizadas a 1\%, com o objetivo de eliminar outliers. Dessa forma, a amostra final resultou em 261 empresas, analisadas no período entre 2009 a 2016. A partir de 2009, as demonstrações financeiras das empresas constantes da amostra já estavam em acordo com os padrões do IFRS (International Financial Reporting Standards). A tabela 1 traz a quantidade de empresas por setor. A categorização setorial utilizada foi do sistema Economática.

Tabela 1: Quantidade de empresas por setor

\begin{tabular}{ccc}
\hline Setor & Quantidade de empresas & Participação (\%) \\
\hline Agro e pesca & 4 & 1,53 \\
Alimentos e bebidas & 11 & 4,21 \\
Comércio & 16 & 6,14 \\
Construção & 19 & 7,28 \\
Eletroeletrônicos & 4 & 1,53 \\
Energia & 40 & 15,33 \\
Outros & 63 & 24,14 \\
Máquinas e equipamentos & 4 & 1,53 \\
Mineração & 3 & 1,15 \\
Mineração não-metais & 3 & 1,15 \\
Papel e celulose & 4 & 1,53 \\
Petróleo e gás & 7 & 2,68 \\
Químico & 7 & 2,68 \\
Siderurgia e metalurgia & 18 & 6,89 \\
Software e dados & 3 & 1,15 \\
Telecomunicações & 5 & 1,91 \\
Têxtil & 20 & 7,66 \\
Transporte & 16 & 6,13 \\
Veículos e peças & $\mathbf{2 6 1}$ & 5,37 \\
\hline Total & 14 &
\end{tabular}

Fonte: Elaborada pelos autores

Observa-se na tabela 1 um elevado fracionamento das empresas por setor. Excluindo o setor outros, o setor de energia corresponde a mais de $15 \%$ do total da amostra. Os demais setores têm uma participação 
inferior a $10 \%$ do total.

\subsection{Definição operacional das variáveis}

O quadro 1 apresenta a construção das variáveis empregadas nos modelos de regressão linear.

Quadro 1: Definição operacional das variáveis de pesquisa

\begin{tabular}{|c|c|}
\hline Variáveis & Fórmula \\
\hline Divida Total Contábil (DTC) & (Dívidas de curto prazo + Dívidas de longo prazo) / Ativo Total \\
\hline Divida Total a Valor de Mercado (DTM) & (Dívidas de curto prazo + Dívidas de longo prazo) / (Exigível \\
& Total + PL a Valor de Mercado) \\
\hline Grau de Intangibilidade (GI) & Valor de Mercado do PL / Valor Contábil do PL \\
\hline Retorno sobre os Ativos (ROA) & EBIT / Ativo Total \\
\hline Market-to-Book value (MB) & (Exigível Total + PL a Valor de Mercado) / Ativo Total \\
\hline Tamanho (TAM) & Logaritmo natural do Ativo Total \\
\hline Tangibilidade (TANG) & (Estoques + Imobilizado) / Ativo Total \\
\hline Pagamento de IR (PIR) & Montante de Pagamento de IR / EBIT \\
\hline Benefício não Relacionado ao IR (BNF) & Montante de Depreciação / Ativo Total \\
\hline
\end{tabular}

PL: Patrimônio Líquido; Valor Contábil do PL: Valor evidenciado no Balanço Patrimonial; Valor de Mercado do PL: Quantidade de ações negociadas no mercado multiplicada pelo preço unitário da ação no último dia útil de cada ano; EBIT: Lucro Antes de juros e Impostos; IR: Imposto de Renda da Pessoa Jurídica.

\section{Fonte: Elaborado pelos autores}

\subsection{Modelos empíricos de análise}

São utilizadas as técnicas de regressão, com dados em painel, OLS (Ordinary Least Square) Pooled e Efeitos Fixos com dummy para tempo. Rodou-se também, a regressão sem dummy para tempo, e os resultados foram muito parecidos. Isso leva a crer que o efeito tempo não é significativo para as variáveis dependentes desse estudo. O teste de Hausman indicou a prevalência por efeitos fixos. Em ambas técnicas foram utilizadas erros-padrão robustos, a fim de atenuar eventuais problemas de heteroscedasticidade.

A análise da relação intangibilidade e valor de mercado (medido pelo market-to-book), como proposto pela hipótese H1, é estimada pela equação (1). Espera-se que haja uma relação positiva entre MB e GI.

$$
M B_{i, t}=\beta_{0}+\beta_{1} G I_{i, t}+\beta_{2} T A M_{i, t}+\beta_{3} T A N G_{i, t}+\beta_{4} P I R_{i, t}+\beta_{5} B N F_{i, t}+\varepsilon_{i, t}
$$

Entretanto, MB (market-to-book value) e GI (grau de intangibilidade) são variáveis que podem ser altamente correlacionadas. Mais adiante o presente artigo discute grau de correlação entre as variáveis de pesquisa. Portanto, substitui-se a variável dependente MB por ROA (retorno sobre os ativos), conforme equação (2). Além do problema da correlação, outro propósito da substituição reside no fato de que tanto $\mathrm{MB}$ quanto ROA são medidas de desempenho econômico, e como tal, espera-se resultados similares.

$$
R O A_{i, t}=\beta_{0}+\beta_{1} G I_{i, t}+\beta_{2} T A M_{i, t}+\beta_{3} T A N G_{i, t}+\beta_{4} P I R_{i, t}+\beta_{5} B N F_{i, t}+\varepsilon_{i, t}
$$

A hipótese H2 é estimada pela equação (3). A relação entre endividamento e market-to-book value (MB) é amplamente pesquisada pela literatura financeira. A variável MB serve como proxy, por exemplo, para oportunidades de crescimento e até mesmo para intangibilidade. As conclusões acerca de tal relacionamento são dúbias, pois as evidências empíricas mostram tanto uma relação positiva quanto negativa. Pela teoria de trade off espera uma relação negativa entre endividamento e market-to-book value. Por outro lado, tanto uma relação negativa quanto positiva encontra respaldo pela teoria de pecking order.

$$
D I V_{i, t}=\beta_{0}+\beta_{1} M B_{i, t}+\beta_{2} R O A_{i, t}+\beta_{3} T A M_{i, t}+\beta_{4} T A N G_{i, t}+\beta_{5} P I R_{i, t}+\beta_{6} D N F_{i, t}+\varepsilon_{i, t}
$$

Por fim, a hipótese H3 testa a relação entre endividamento e intangibilidade, a partir da equação (4). Espera-se uma relação inversa, conforme abordado na fundamentação teórica deste trabalho.

$$
D I V_{i, t}=\beta_{0}+\beta_{1} G I_{i, t}+\beta_{2} R O A_{i, t}+\beta_{3} T A M_{i, t}+\beta_{4} T A N G_{i, t}+\beta_{5} P I R_{i, t}+\beta_{6} D N F_{i, t}+\varepsilon_{i, t}
$$




\section{Análise e Discussão dos Resultados}

A tabela 2 mostra as estatísticas descritivas das variáveis de estudo. O endividamento médio a valor contábil (DTC) é de 40\%, o que é muito próximo do endividamento a valor de mercado (DTC) de $37 \%$. O grau de intangibilidade (GI) de 1,858 mostra que o valor de mercado do patrimônio líquido das empresas da amostra é quase o dobro do valor contábil do patrimônio líquido. A média rentabilidade sobre os ativos (ROA) foi de $8,5 \%$ e a média da tangibilidade (TANG) representa 32,8\% do ativo total.

Tabela 2: Estatísticas Descritivas

\begin{tabular}{ccccccc}
\hline Var. & Obs & Média & Desvio padrão & Mínimo & Máximo \\
\hline DTC & 1677 & 0,400 & 0,235 & 0 & 0,818 \\
DTM & 1677 & 0,370 & 0,256 & 0 & 0,858 \\
GI & 1677 & 1,858 & 1,604 & 0,186 & 6,275 \\
TAM & 1677 & 14,791 & 1,456 & 12,184 & 17,435 \\
ROA & 1677 & 0,085 & 0,057 & 0,008 & 0,221 \\
TANG & 1677 & 0,328 & 0,232 & 0,002 & 0,735 \\
PIR & 1677 & 0,185 & 0,175 & 0 & 0,685 \\
BNF & 1642 & 0,027 & 0,018 & 0,001 & 0,064 \\
MB & 1677 & 1,036 & 0,642 & 0,288 & 2,764 \\
\hline
\end{tabular}

Fonte: Elaborada pelos autores

A tabela 3 mostra a matriz de correlação com seus respectivos p-values entre todas as variáveis de estudo. É possível observar que a correlação entre GI (grau de intangibilidade) e MB (market-to-book value) alcançou 0,783, estatisticamente significante. Tal resultado evidencia que o MB pode ser proxy de grau de intangibilidade. Em relação à dívida, a correlação entre DTC (dívida total a valor contábil) e DTM (dívida total a valor de mercado) é de 0,717 , estatisticamente significante, o que é esperado. Os demais graus de correlação entre as variáveis ficaram abaixo de 0,60 , sendo a maioria estatisticamente significante.

Tabela 3: Correlação entre as variáveis de pesquisa

\begin{tabular}{|c|c|c|c|c|c|c|c|c|c|}
\hline Var. & DTC & DTM & GI & MB & ROA & TAM & TANG & PIR & BNF \\
\hline DTC & 1,000 & & & & & & & & \\
\hline DTM & $\begin{array}{c}0,717 \\
(0,000)\end{array}$ & 1,000 & & & & & & & \\
\hline GI & $\begin{array}{c}0,090 \\
(0,000)\end{array}$ & $\begin{array}{c}-0,435 \\
(0,000)\end{array}$ & 1,000 & & & & & & \\
\hline MB & $\begin{array}{l}-0,145 \\
(0,000)\end{array}$ & $\begin{array}{l}-0,551 \\
(0,000)\end{array}$ & $\begin{array}{c}0,783 \\
(0,000)\end{array}$ & 1,000 & & & & & \\
\hline ROA & $\begin{array}{l}-0,151 \\
(0,000)\end{array}$ & $\begin{array}{c}-0,366 \\
(0,000)\end{array}$ & $\begin{array}{c}0,424 \\
(0,000)\end{array}$ & $\begin{array}{c}0,475 \\
(0,000)\end{array}$ & 1,000 & & & & \\
\hline TAM & $\begin{array}{c}0,303 \\
(0,000)\end{array}$ & $\begin{array}{c}0,133 \\
(0,000)\end{array}$ & $\begin{array}{c}0,053 \\
(0,028)\end{array}$ & $\begin{array}{c}0,026 \\
(0,287)\end{array}$ & $\begin{array}{c}-0,069 \\
(0,004)\end{array}$ & 1,000 & & & \\
\hline TANG & $\begin{array}{c}0,055 \\
(0,022)\end{array}$ & $\begin{array}{c}0,125 \\
(0,000)\end{array}$ & $\begin{array}{l}-0,119 \\
(0,000)\end{array}$ & $\begin{array}{l}-0,145 \\
(0,000)\end{array}$ & $\begin{array}{l}-0,127 \\
(0,000)\end{array}$ & $\begin{array}{c}-0,145 \\
(0,000)\end{array}$ & 1,000 & & \\
\hline PIR & $\begin{array}{l}-0,129 \\
(0,000)\end{array}$ & $\begin{array}{l}-0,130 \\
(0,000)\end{array}$ & $\begin{array}{c}0,011 \\
(0,646)\end{array}$ & $\begin{array}{c}0,040 \\
(0,098)\end{array}$ & $\begin{array}{l}-0,185 \\
(0,000)\end{array}$ & $\begin{array}{c}-0,014 \\
(0,555)\end{array}$ & $\begin{array}{l}-0,036 \\
(0,138)\end{array}$ & 1,000 & \\
\hline BNF & $\begin{array}{c}0,126 \\
(0,000)\end{array}$ & $\begin{array}{c}-0,002 \\
(0,913)\end{array}$ & $\begin{array}{c}0,109 \\
(0,000)\end{array}$ & $\begin{array}{c}0,093 \\
(0,000)\end{array}$ & $\begin{array}{c}0,106 \\
(0,000)\end{array}$ & $\begin{array}{c}0,097 \\
(0,000)\end{array}$ & $\begin{array}{c}0,327 \\
(0,000)\end{array}$ & $\begin{array}{c}0,019 \\
(0,437)\end{array}$ & 1,000 \\
\hline
\end{tabular}

Os valores $p$-value estão entre parênteses

\section{Fonte: Elaborada pelos autores}

Os modelos empíricos foram aplicados por meio da técnica econométrica com dados em painel com o objetivo de testar as três hipóteses propostas por este estudo. A tabela 4 mostra os resultados das hipóteses de pesquisa utilizando painel com efeitos fixos. 
Tabela 4: Dados em painel com efeitos fixos

\begin{tabular}{|c|c|c|c|c|c|c|}
\hline & \multicolumn{2}{|c|}{ Hipótese 1} & \multicolumn{2}{|c|}{ Hipótese 2} & \multicolumn{2}{|c|}{ Hipótese 3} \\
\hline Var. Ind. & $\begin{array}{c}\text { Var. Dep. } \\
\text { MB }\end{array}$ & $\begin{array}{c}\text { Var. Dep. } \\
\text { ROA }\end{array}$ & $\begin{array}{c}\text { Var. Dep. } \\
\text { DTC }\end{array}$ & $\begin{array}{c}\text { Var. Dep. } \\
\text { DTM }\end{array}$ & $\begin{array}{l}\text { Var. Dep. } \\
\text { DTC }\end{array}$ & $\begin{array}{c}\text { Var. Dep. } \\
\text { DTM }\end{array}$ \\
\hline Cons & $\begin{array}{c}3,725^{* * *} \\
(0,370)\end{array}$ & $\begin{array}{c}0,472 * * * \\
(0,062)\end{array}$ & $\begin{array}{c}-1,166^{* * * *} \\
(0,212)\end{array}$ & $\begin{array}{c}-0,730 * * * \\
(0,232)\end{array}$ & $\begin{array}{c}-1,302^{* * *} \\
(0,211)\end{array}$ & $\begin{array}{c}-1,177 * * * \\
(0,237)\end{array}$ \\
\hline MB & & & $\begin{array}{c}0,008 \\
(0,016)\end{array}$ & $\begin{array}{c}-0,177 * * * \\
(0,018)\end{array}$ & & \\
\hline ROA & & & $\begin{array}{l}-0,184 \\
(0,111)\end{array}$ & $\begin{array}{l}-0,133 \\
(0,125)\end{array}$ & $\begin{array}{c}-0,248 * * \\
(0,109)\end{array}$ & $\begin{array}{c}-0,287 * * \\
(0,126)\end{array}$ \\
\hline GI & $\begin{array}{c}0,226 * * * \\
(0,020)\end{array}$ & $\begin{array}{c}0,006^{* * *} \\
(0,001)\end{array}$ & & & $\begin{array}{c}0,023 * * * \\
(0,006)\end{array}$ & $\begin{array}{c}-0,053 * * * \\
(0,006)\end{array}$ \\
\hline TAM & $\begin{array}{c}-0,207 * * * \\
(0,023)\end{array}$ & $\begin{array}{c}-0,026^{* * *} * \\
(0,004)\end{array}$ & $\begin{array}{c}0,104 * * * \\
(0,013)\end{array}$ & $\begin{array}{c}0,086^{* * *} \\
(0,015)\end{array}$ & $\begin{array}{c}0,111^{* * *} \\
(0,013)\end{array}$ & $\begin{array}{c}0,111 * * * \\
(0,015)\end{array}$ \\
\hline TANG & $\begin{array}{c}-0,014 \\
(0,065)\end{array}$ & $\begin{array}{l}-0,000 \\
(0,012)\end{array}$ & $\begin{array}{c}-0,032 \\
(0,041)\end{array}$ & $\begin{array}{c}-0,110^{* * *} \\
(0,040)\end{array}$ & $\begin{array}{c}-0,043 \\
(0,040)\end{array}$ & $\begin{array}{c}-0,100 * * \\
(0,039)\end{array}$ \\
\hline PIR & $\begin{array}{c}0,074 \\
(0,052)\end{array}$ & $\begin{array}{c}-0,099 * * * \\
(0,009)\end{array}$ & $\begin{array}{c}-0,049^{*} \\
(0,021)\end{array}$ & $\begin{array}{l}-0,007 \\
(0,029)\end{array}$ & $\begin{array}{c}-0,043^{* *} \\
(0,020)\end{array}$ & $\begin{array}{l}-0,038 \\
(0,028)\end{array}$ \\
\hline $\mathrm{BNF}$ & $\begin{array}{c}-1,864 \\
(1,308) \\
\end{array}$ & $\begin{array}{c}0,518 * * * \\
(0,167) \\
\end{array}$ & $\begin{array}{c}1,566^{* * *} \\
(0,505) \\
\end{array}$ & $\begin{array}{c}1,897 * * * \\
(0,538) \\
\end{array}$ & $\begin{array}{c}1,842 * * * \\
(0,500) \\
\end{array}$ & $\begin{array}{c}2,127 * * * \\
(0,572) \\
\end{array}$ \\
\hline Dummy tempo & Sim & Sim & Sim & Sim & Sim & Sim \\
\hline Observações & 1.642 & 1.642 & 1.642 & 1.642 & 1.642 & 1.642 \\
\hline R-quadrado & 0,377 & 0,070 & 0,107 & 0,221 & 0,118 & 0,118 \\
\hline $\mathrm{N}^{\mathrm{o}}$ Firmas & 239 & 239 & 239 & 239 & 239 & 239 \\
\hline
\end{tabular}

\section{Fonte: Elaborada pelos autores}

A hipótese 1 sugere uma relação direta entre ativos intangíveis e criação de valor de mercado. Os intangíveis são representados pela variável grau de intangibilidade (GI) e o valor de mercado por market-tobook-value (MB). Entretanto, como GI e MB são altamente correlacionadas, utilizou-se também, outra medida de desempenho econômico, o retorno sobre ativos (ROA). De acordo com os resultados, a relação entre o MB e o GI é significante e positiva $(0,226)$. A tabela 4 também mostra que a relação entre ROA e GI é significante e positiva $(0,006)$. Embora os dois resultados sejam estatisticamente significantes, o grau de intangibilidade em relação ao market-to-book value $(\mathrm{MB})$ apresentou maior significância econômica em comparação com o ROA. Dessa maneira, o grau de intangibilidade influencia em maior intensidade o MB. Os resultados confirmam a hipótese 1 e reforçam que o grau de intangibilidade é positivamente relacionado com a criação de valor de mercado e com o retorno sobre ativos.

O tamanho (TAM) da empresa é negativamente relacionado com MB e ROA (-0,207 e -0,026, respectivamente), com prevalência de significância econômica para MB. Quanto maior o tamanho da empresa, menor é sua criação de valor e rentabilidade. Isso pode ser explicado pelo fato de que empresas maiores possuem elevados custos operacionais, acarretando em uma diminuição dos lucros, prejudicando a criação de valor. Adicionalmente, o retorno sobre ativos (ROA) se relacionou negativamente com o PIR ($0,099)$ e positivamente com o BNF $(0,518)$. Tais resultados são coerentes com a teoria do trade off, em que empresas mais lucrativas tendem a um maior grau de endividamento, se valendo do benefício fiscal da dívida e por conseguinte, do benefício não relativo ao imposto de renda.

A hipótese 2 testa a relação inversa entre dívida e criação de valor de mercado. As variáveis dependentes utilizadas foram dívida total a valor contábil (DTC) e dívida total a valor de mercado (DTM). De acordo com os resultados da tabela 4, a variável MB não apresentou resultado estatisticamente significante com o DTC, porém, quando comparado com o DTM, demonstra uma relação negativa e estatística e economicamente significante $(-0,177)$. Indica que quanto maior o valor de mercado da empresa menor é seu endividamento. A variável MB também capta oportunidades de crescimento e sua relação negativa com o endividamento está em linha com a teoria do pecking order. Para o pecking order as pesquisas têm mostrado que pode haver uma relação negativa, pois as empresas devem manter um endividamento baixo, a fim de explorar a capacidade de dívida (flexibilidade financeira), exatamente para evitar recorrer às ações.

Adicionalmente, ambas as variáveis de dívida se relacionaram positivamente com o tamanho da empresa $(0,104$ e 0,086$)$. Isto demonstra que quanto maior o tamanho da empresa, maior é seu endividamento, corroborando as teorias do trade off e pecking order de acordo com Brito, Corrar e Batistella (2007). Fonseca, 
Silveira e Hiratuka (2016) explicam esse resultado pelo fato de que grandes empresas possuem um custo menor para seus financiamentos (principalmente a longo prazo) e acabam obtendo um endividamento maior. De acordo com Bastos e Nakamura (2009), esta relação positiva entre endividamento e tamanho pode ser explicada pela facilidade de financiamento a longo prazo que empresas maiores possuem, corroborando a teoria do trade off. O endividamento (DTC e DTM) se relaciona positivamente com o benefício fiscal $(1,566 \mathrm{e}$ 1,897), fortalecendo a teoria do trade off. Por fim, a relação inversa entre DTM e tangibilidade (TANG) (0,110) encontra respaldo na teoria do pecking order, pois empresas possuidoras de mais ativos tangíveis reduzem a assimetria de informação entre gestores e mercado. Assim, as firmas preferem emitir ações à dívidas.

A hipótese 3 testa a relação inversa entre ativos intangíveis e dívida. A dívida contábil (DTC) obteve uma relação direta e estatisticamente significante com a intangibilidade $(\mathrm{GI})(0,023)$. Pela teoria de agência tal qual pesquisada por Jensen (1986), a dívida serviria como um limitador para as decisões gerenciais arbitrárias. Sendo assim, ativos intangíveis, que representam boas oportunidades de crescimento para a empresa possuem como contrapartida um maior nível de dívidas, exatamente para frear possíveis tomadas de decisão arbitrárias. Já em relação à relação entre DTM e GI, o resultado foi negativo e estatisticamente significante $(-0,053)$, condizente com os trabalhos de Kayo, Teh e Basso (2006) e Kayo, Patrocínio e Martin (2009). Empresas altamente intangíveis priorizam folga financeira para investimentos futuros, ao mesmo tempo em que tais ativos intangíveis dificilmente são utilizados como garantia para dívida. Estes resultados são amparados tanto pela teoria do pecking order quanto trade off.

Essa incoerência entre os resultados com DTC e DTM pode ser explicada por Welch (2004) que aponta que o valor contábil da dívida não representa apropriadamente as condições econômicas da empresa, reforçando ainda que as medidas contábeis "enxergam para trás" (visão estática), enquanto as medidas de mercado "enxergam pra frente” (visão dinâmica).

O ROA obteve resultados negativos e significantes com a dívida $(-0,248$ e -0,287) com DTC e DTM, respectivamente. Tal resultado está de acordo com a teoria do pecking order, pois as empresas preferem utilizar primeiramente recursos internos. Empresas mais lucrativas tendem a ser menos endividadas, pois o lucro é a principal fonte de capital. Por fim, as demais variáveis obtiveram resultados similares aos resultados encontrados na hipótese 2 .

Tabela 5: Dados em painel em pooled (OLS)

\begin{tabular}{|c|c|c|c|c|c|c|}
\hline & \multicolumn{2}{|c|}{ Hipótese 1} & \multicolumn{2}{|c|}{ Hipótese 2} & \multicolumn{2}{|c|}{ Hipótese 3} \\
\hline Var. Ind. & $\begin{array}{c}\text { Var. Dep. } \\
\text { MB }\end{array}$ & $\begin{array}{c}\text { Var. Dep. } \\
\text { ROA }\end{array}$ & $\begin{array}{c}\text { Var. Dep. } \\
\text { DTC }\end{array}$ & $\begin{array}{c}\text { Var. Dep. } \\
\text { DTM }\end{array}$ & $\begin{array}{c}\text { Var. Dep. } \\
\text { DTC }\end{array}$ & $\begin{array}{c}\text { Var. Dep. } \\
\text { DTM }\end{array}$ \\
\hline Cons & $\begin{array}{c}0,606 * * * \\
(0,100)\end{array}$ & $\begin{array}{c}0,147 * * * \\
(0,013)\end{array}$ & $\begin{array}{c}-0,236 * * * \\
(0,059)\end{array}$ & $\begin{array}{c}0,237 * * * \\
(0,056)\end{array}$ & $\begin{array}{c}-0,232 * * * \\
(0,059)\end{array}$ & $\begin{array}{c}0,179 * * * \\
(0,060)\end{array}$ \\
\hline MB & & & $\begin{array}{c}-0,032 * * * \\
(0,009)\end{array}$ & $\begin{array}{c}-0,189 * * * \\
(0,009)\end{array}$ & & \\
\hline ROA & & & $\begin{array}{c}-0,533 * * * \\
(0,110)\end{array}$ & $\begin{array}{c}-0,672 * * * \\
(0,104)\end{array}$ & $\begin{array}{c}-1,024 * * * \\
(0,106)\end{array}$ & $\begin{array}{c}-1,079 * * * \\
(0,107)\end{array}$ \\
\hline GI & $\begin{array}{c}0,318^{* * *} \\
(0,005)\end{array}$ & $\begin{array}{c}0,014 * * * \\
(0,000)\end{array}$ & & & $\begin{array}{c}0,026^{* * *} \\
(0,003)\end{array}$ & $\begin{array}{c}-0,052 * * * \\
(0,003)\end{array}$ \\
\hline TAM & $\begin{array}{c}-0,010 \\
(0,006)\end{array}$ & $\begin{array}{c}-0,005 * * * \\
(0,000)\end{array}$ & $\begin{array}{c}0,047 * * * \\
(0,003)\end{array}$ & $\begin{array}{c}0,026^{* * *} \\
(0,003)\end{array}$ & $\begin{array}{c}0,044 * * * \\
(0,003)\end{array}$ & $\begin{array}{c}0,026^{* * *} \\
(0,003)\end{array}$ \\
\hline TANG & $\begin{array}{c}-0,186^{* * *} \\
(0,043)\end{array}$ & $\begin{array}{c}-0,035 * * * \\
(0,005)\end{array}$ & $\begin{array}{c}0,025 \\
(0,025)\end{array}$ & $\begin{array}{c}0,034 \\
(0,024)\end{array}$ & $\begin{array}{l}0,047^{*} \\
(0,025)\end{array}$ & $\begin{array}{c}0,057^{* *} \\
(0,025)\end{array}$ \\
\hline PIR & $\begin{array}{c}0,119 * * \\
(0,053)\end{array}$ & $\begin{array}{c}-0,065^{* * *} \\
(0,007)\end{array}$ & $\begin{array}{c}-0,193 * * * \\
(0,031)\end{array}$ & $\begin{array}{c}-0,185 * * * \\
(0,029)\end{array}$ & $\begin{array}{c}-0,229 * * * \\
(0,030)\end{array}$ & $\begin{array}{c}-0,234 * * * \\
(0,031)\end{array}$ \\
\hline $\mathrm{BNF}$ & $\begin{array}{l}1,062^{*} \\
(0,556)\end{array}$ & $\begin{array}{c}0,400 * * * \\
(0,073)\end{array}$ & $\begin{array}{c}1,496 * * * \\
(0,322) \\
\end{array}$ & $\begin{array}{c}0,500 \\
(0,304) \\
\end{array}$ & $\begin{array}{c}1,232 * * * \\
(0,318) \\
\end{array}$ & $\begin{array}{c}0,431 \\
(0,323) \\
\end{array}$ \\
\hline Dummy tempo & Sim & Sim & Sim & Sim & Sim & Sim \\
\hline Observações & 1.642 & 1.642 & 1.642 & 1.642 & 1.642 & 1.642 \\
\hline R-quadrado & 0,654 & 0,247 & 0,158 & 0,359 & 0,178 & 0,278 \\
\hline $\mathrm{N}^{\circ}$ Firmas & 239 & 239 & 239 & 239 & 239 & 239 \\
\hline
\end{tabular}

Fonte: Elaborada pelos autores

A tabela 5 traz os resultados para a regressão linear, com dados em painel pooled OLS. A hipótese 1 é confirmada, evidenciando uma relação direta entre grau de intangibilidade (GI) e market-to-book value (MB) 
$(0,318)$ e retorno sobre ativos (ROA) $(0,014)$. Tais resultados são muito parecidos com os da tabela 4 , que utilizou dados em painel com efeitos fixos. A tangibilidade (TANG) mostrou-se negativamente relacionada com MB e ROA (-0,186 e -0,035, respectivamente), divergindo dos resultados mostrados na tabela 4. Essa situação indica que empresas menos tangíveis, em tese, possuidoras de elevados ativos intangíveis, apresentam desempenho econômico melhor.

Com relação à hipótese 2, o market-to-book value apresentou uma relação negativa e estatisticamente significante com DTC $(-0,032)$ e DTM $(-0,189)$, também coerente com os resultados presentes na tabela 4 . As demais variáveis de controle obtiveram resultados semelhantes com os da tabela 4.

Considerando a hipótese 3, a relação entre ativos intangíveis e dívida também foi muito parecida quando se utiliza painel com efeitos fixos (tabela 4). Relação positiva e estatisticamente significante para DTC $(0,026)$ e negativa e estatisticamente negativa para DTM (-0,052). Mais uma vez, a tangibilidade (TANG) mostrou uma relação inversa com DTM. Na tabela 5, com pooled, há uma relação direta. Isso é um ponto que merece ser aprofundado com o emprego de outras técnicas e/ou modelos econométricos mais sofisticados.

\section{Considerações finais}

O presente trabalho foi desenvolvido com o objetivo de identificar a relação entre ativos intangíveis, dívida e criação de valor de mercado para as empresas brasileiras de capital aberto. De fato, um desafio presente é a mensuração do valor criado pelos ativos intangíveis. Muitos estudos empíricos utilizam como proxy para grau de intangibilidade o market-to-book value.

Partiu-se do pressuposto que a diferença positiva entre valor de mercado da empresa e seu valor contábil reside, em parte, no grau de intangibilidade da empresa. Adicionalmente, a variável market-to-book value também serve como proxy para oportunidades de crescimento de uma empresa, e deve-se ter o cuidado que nem sempre boas oportunidades de crescimento advém exclusivamente dos ativos intangíveis possuídos pela empresa. Entretanto, há certo consenso na seara acadêmica de que a variável market-to-book value capta parte do valor criado pela empresa em função dos seus ativos intangíveis. Para este estudo foi realizada uma adaptação entre as variáveis grau de intangibilidade e market-to-book value, a fim de que o grau de intangibilidade captasse tão somente a diferença entre valor de mercado da empresa e seu valor contábil, ao passo que o market-to-book value considerasse o valor criado para a empresa como um todo, sendo o spread de valor o Patrimônio Líquido (PL) a valor de mercado, em vez do PL contábil.

O grau de intangibilidade apresentou relação direta com a criação de valor de mercado das empresas, tal como foi corroborado por este estudo. Dessa forma, reforça-se a relação direta entre estas duas variáveis de pesquisa, tornando esse resultado relevante para as empresas que investem em ativos intangíveis. Tal evidência indica que, de fato, os ativos intangíveis de propriedade de uma empresa, como P\&D, capital intelectual, marca, boa reputação e capacidade de inovar, entre outros, pode promover uma valoração econômica da empresa.

Por outro lado, empresas com processo de criação de valor mais acentuado parecem ser menos endividadas. A variável market-to-book value pode ser utilizada como proxy para oportunidades de crescimento. Uma das possíveis conclusões para a relação inversa entre dívida e criação de valor se ampara no benefício da folga financeira, crucial em momentos de investimentos intensivos, estando de acordo com a teoria do pecking order. Se os recursos internos não forem suficientes para financiarem os investimentos, a próxima opção de recursos vem da dívida, tal como apregoado pela teoria do pecking order. Esta pesquisa evidenciou uma relação inversa entre dívida e criação de valor, estando, em tese, alinhada com a teoria de pecking order.

A última evidência está na relação dúbia entre ativos intangíveis e dívida. Considerando a dívida a valor de mercado, há uma relação inversa entre ativos intangíveis e dívida, o que coaduna com a teoria do pecking order, uma vez que o grau de intangibilidade é proxy para oportunidades de crescimento. Aqui também cabe o reforço da teoria do trade off. Como os ativos intangíveis são menos utilizados como garantia (colaterais) da dívida e tendo maiores custos de transação, é coerente que sejam financiados com fundos internos ou capital próprio. Entretanto, para a dívida a valor contábil, a relação se mostra positiva. Essa constatação pode estar embasada na teoria de agência (JENSEN, 1986), que indica haver uma relação direta entre oportunidades de crescimento (grau de intangibilidade) e dívida, pois a dívida limitaria a arbitrariedade das decisões gerenciais. 
Como a dívida a valor contábil é aquela registrada em balanço patrimonial e de fácil obtenção e evidenciação, o montante da dívida contábil serviria como freio para a tomada de decisão arbitrária quanto aos investimentos futuros da empresa.

Cabe frisar algumas limitações deste estudo, tais como limitações econométricas, operacionalização de variáveis (principalmente mensurar com mais propriedade o grau de intangibilidade) e a não consideração de eventos econômicos exógenos. As pesquisas futuras, nessa área do conhecimento, podem avançar ao especificar melhor os ativos intangíveis e as janelas de oportunidades para investimentos. Além disso, a consideração do setor é algo relevante, uma vez que há setores mais intensivos em intangíveis. Também, as variáveis exógenas, como condições do ambiente econômico e legal podem trazer contribuições ao tema.

\section{REFERÊNCIAS}

BAH, R.; DUMONTIER, P. R\&D intensity and corporate financial policy: some international evidence. Journal of Business Finance \& Accounting, Oxford, v.28, n.5-6, p.671- 692, Jun. 2001.

BALAKRISHNAN, S.; FOX, I. Asset specificity, firm heterogeneity and capital structure. Strategic Management Journal, v. 14, p. 3-16, 1993.

BASTOS, D. D.; NAKAMURA, W. T. Determinantes da estrutura de capital das companhias abertas no Brasil, México e Chile no período 2001-2006. Revista Contabilidade \& Finanças da USP, v. 20, n. 50, p. 75-94, 2009.

BESSLER, W.; DROBETZ, W.; K. R. Factors affecting capital structure decisions. In: Capital Structure and Corporate Financing Decisions - Theory, evidence, and practice. Kolb Series in Finance. John Wiley\&Sons, 2011.

BRITO, G. A. S.; CORRAR, L. J.;BATISTELlA, F. D. Fatores determinantes da Estrutura de Capital das maiores empresas que atuam no Brasil. Revista de Contabilidade e Finanças da USP. v. 43, p. 9-19, 2007.

COMITÊ DE PRONUNCIAMENTOS CONTÁBEIS. CPC-04 (R1) - Ativos Intangíveis. Disponível em: $<$ www.cpc.org.br/CPC/Documentos-Emitidos/Pronunciamentos/>

CORREA C. A.; BASSO, L. F. C.; NAKAMURA W. T; A estrutura de capital das maiores empresas brasileiras: Análise empírica das teorias de pecking order e trade-off, usando panel data. Revista de Administração Mackenie, v. 14, n. 4 p. 106-133, 2013.

FAULKENDER, M.; PETERSEN, M. A. Does the source of capital affect capital structures? The Review of Financial Studies, v. 19, n. 1, p. 45-79, 2006.

FONSECA, C.V.C.; SILVEIRA, R.L.F.; HIRATUKA, C. A relação entre governança corporativa e a estrutura de capital das empresas brasileiras no período 2000 a 2013. Enfoque Reflexão Contábil, v. 35, n. 2, p. 35-52, 2016.

FRANK, M. Z.; GOYAL, V. K. Capital structures decisions: Which factors are reliably important? Financial Management, v, 38, p. 1-37, 2009.

JENSEN, M. Agency costs of free cash flow, corporate finance and takeovers. The American Economic Review, v. 76, n. 2, p. 323-329, 1986.

JUCÁ, M. N.; CAMPOS, A.L.S.; BASTOS, D.D.; MENDES, E.A. Endividamento e estrutura de ativos: Evidências no Brasil. Revista de Finanças Aplicadas, v.7, n.1, p.1-19, 2016.

KAYO, E. K.; KIMURA, H.; MARTIN, D. M. L.; NAKAMURA, W. T. Ativos intangíveis, ciclo de vida e criação de valor. Revista de Administração Contemporânea, v. 10, n. 3, 2006.

KAYO, E. K.; TEH, C. C.; BASSO, L. F. C. Ativos intangíveis e estrutura de capital: a influência das marcas e patentes sobre o endividamento. RAUSP Revista de Administração, v. 41, n. 2, p. 158-168, 2006. 
KAYO, E. K.; PATROCÍNIO, M. R.; MARTIN, D. M. L. Intangibilidade e criação de valor em aquisições: o papel moderador do endividamento. RAUSP Revista de Administração, v. 44, n. 1, art. 5, p. 59-69, 2009.

LEMMON, Michael L.; ROBERTS, Michael R.; ZENDER, Jaime F. Back to the beginning: Persistence and the cross-section of corporate capital structure. The Journal of Finance, v. 63, n. 4, p. 1575-1608, 2008.

LEV, B. Intangibles: management and reporting. Washington: Brookings, 2001.

MEDRADO, F.; CELLA, G.; PEREIRA, J. V.; DANTAS, J. A. Relação entre o nível de intangibilidade dos ativos e o valor de mercado das empresas. Revista de Contabilidade e Organizações, v. 10, n. 28, p. 32-44, 2016.

MODIGLIANI, F.; MILlER, M. H. The cost of capital, corporation finance and the theory of investment. American Economic Review, v. 48, p. 261-297, 1958.

MODiGliANi, F.; MILLER, M. H. Corporate income taxes and the cost of capital: a correction. American Economic Review, v. 53, n. 3, p. 433- 443, 1963.

MYERS, S. C. The capital structure puzzle. The Journal of Finance, American Finance Association, Chicago, v. 39, n. 3, p. 575-592, 1984.

MYERS, S.C..; MAJLUF, N. S. Corporate financing and investment decisions when firms have information that investors do not have. Journal of Financial Economics, v. 13, n. 2, p. 187-222, 1984.

O'BRIEN, J. The capital structure implications of pursuing a strategy of innovation. Strategic Management Journal, v. 24, n. 5, p. 415-431, 2003.

PATROCÍNIO, M. R.; KAYO, E. K.; KIMURA, H. Aquisição de empresas, intangibilidade e criação de valor: um estudo de evento. RAUSP Revista de Administração, v. 42, n. 2, p. 205-215, 2007.

PEROBELLI, F. F. C.; FAMÁ, R. Determinantes da estrutura de capital: aplicação a empresas de capital aberto brasileiras. RAUSP Revista de Administração, v. 37, n. 3, p. 33-46, 2002.

PEREZ, M. M.; FAMÁ, R. Ativos intangíveis e o desempenho empresarial. Revista Contabilidade \& Finanças - USP, v. 17, n. 40, p. 7-24, 2006.

PEREZ, M.; FAMÁ, R. Características estratégicas dos ativos intangíveis e o desempenho econômico da empresa. Unisanta Law and Social Science, v. 4, n. 2, p. 107-123, 2015.

RAJAN, R.; ZINGALES, L. What do we know about capital structure? Some evidence from international data. The Journal of Finance, v. 50, n. 5, p. 1421-60, 1995.

SALIBA, J. A.; BASSO, L. F. C.; BRAUNE, E. S.; KIMURA, H. O papel dos intangíveis na criação de valor: uma aplicação para o setor de bens de consumo do mercado norte-americano. Revista Práticas em Contabilidade e Gestão, v. 1, n. 1, p. 66-87, 2013.

SPRENGER, K. B.; SILVESTRE, A. O.; BRUNOZI JÚNIOR, A. C.; KRONBAUER, C. A. Intensidades das Intangibilidades e Desempenhos Econômico-financeiros em Empresas dos Países do GLENIF. Revista de Gestão, Finanças e Contabilidade, v. 7, n. 1, p. 121-148, 2017.

TITMAN, S.; WESSELS, R. The determinants of capital structure choice. The Journal of Finance, v. 43, n. 1, p. 1-19, mar. 1988.

VICENTE-LORENTE, J. D. Specificity and opacity as resource-based determinants of capital structure: Evidence for Spanish manufacturing firms. Strategic Management Journal, v. 22, p. 157-177, 2001.

WELCH, I. Capital structure and stock returns. Journal of Political Economy, v. 112, n. 1, p. 106-31, 2004. 